\title{
Efficiency improvement opportunities for televisions in India: implications for market transformation programs
}

\author{
Won Young Park • Amol Phadke • Nihar Shah
}

Received: 24 June 2013 / Accepted: 5 February 2014 /Published online: 15 March 2014

(C) The Author(s) 2014. This article is published with open access at Springerlink.com

\begin{abstract}
Televisions (TVs) account for a significant portion of residential appliance electricity consumption in India, and TV shipments in India are expected to continue to increase. We assess the market trends in the energy efficiency of TVs that are likely to occur without any additional policy intervention and estimate that TV efficiency will likely improve with saving potential of 6 terawatt-hours (TWh) per year in 2020, compared to today's technology. We discuss various energy-efficiency improvement options and evaluate the cost-effectiveness of three of them, at least one of which improves efficiency by at least $20 \%$ costeffectively beyond these ongoing market trends. We provide insights for policies and programs that can be used to accelerate the adoption of efficient technologies to capture the cost-effective energy savings potential from TVs which we estimate to be $3.4 \mathrm{TWh}$ per year in 2020 .
\end{abstract}

Keywords India $\cdot$ TV energy efficiency Cost-effectiveness $\cdot$ Market transformation

\section{Introduction}

The total global television (TV) electricity consumption was estimated to be more than 250 terawatt-hours

W. Y. Park $(\bowtie) \cdot$ A. Phadke $\cdot$ N. Shah

Environmental Energy Technologies Division, Lawrence

Berkeley National Laboratory,

Berkeley, CA, USA

e-mail: WYPark@lbl.gov
[TWh] in 2008, i.e., more than $5 \%$ of total global residential electricity consumption (International Energy Agency IEA 2009). The total electricity consumption in India was estimated to be 472 TWh in 2005 , and TVs accounted for $3 \%$ of this electricity consumption (i.e., $14 \mathrm{TWh}$ or $17 \%$ of electricity consumed in residential appliances) (de la Rue du Can et al. 2009). In addition, while the market share of cathode ray tube (CRT) TVs in India has been significantly decreasing since 2011, the average TV screen size (measured diagonally) is expected to increase from 21 in. in 2011 to 29 in. in 2016 due to the market transition toward flatpanel TVs (DisplaySearch 2012a; 2012e).

An assessment of efficiency improvement opportunities for TVs is needed for two reasons - first, to correct market failures such as uncaptured economic and environmental benefits available from TV energyconsumption reduction through cost-effective ${ }^{1}$ efficiency improvements and second, to account for the ongoing large-scale transition from cold cathode fluorescent lamp (CCFL) backlit liquid crystal display (CCFLLCD) TVs to light emitting diode (LED) backlit LCD (LED-LCD) TVs in designing market transformation programs such as standards, labels, or incentives in a timely manner (Park et al. 2013). TV manufacturing is highly globalized, and LCD TVs in India are likely to increase significantly within the next 3-4 years, from

\footnotetext{
${ }^{1}$ In this analysis, cost-effectiveness is defined as cost of conserved electricity (CCE), the annualized investment in more expensive equipment or component needed to provide a unit of electricity saved (KWh), less than electricity price.
} 
$43 \%$ of total TV shipments in 2012 to $95 \%$ in 2015 respectively, following the global TV market transition (DisplaySearch 2012a). Hence, the TV technology assessment and the cost-effectiveness of TV efficiency improvement options recently presented in Park et al. 2013 are applicable to India.

This paper focuses on LCD TVs which are expected to dominate the Indian TV market, amounting to an expected $95 \%$ of Indian TV shipments by 2015 (DisplaySearch 2012a). We consider efficiency improvement options that are discussed more fully in Park et al. 2011, 2013 and new types of TVs designed for emerging markets such as India. Although the rapid evolution of technology in the display market makes a forecast over a longer time scale uncertain, in this paper, we assess the impacts of a short-term action, which is assumed to occur by 2015 , on mid-term electricitydemand reduction by 2020 . We obtained the data for this paper primarily from the following sources: review of the literature including publicly available market information, technical reports, commercially available DisplaySearch data sets, ${ }^{2}$ the U.S. ENERGY STAR data base, ${ }^{3}$ and interviews with manufacturers and experts in the field.

The remainder of this paper is organized as follows: First, we present an overview of the India TV market and technology trends. Second, we discuss technologically feasible energy-efficiency improvement options, and adoption trends of such options. We also review recent developments in low-cost LED-LCD TVs designed to be more affordable than conventional LEDLCD TVs. Third, we present a cost of conserved electricity (CCE) analysis to assess the cost-effectiveness of options identified. Fourth, we offer suggestions for accelerating the adoption of efficient technologies, and

\footnotetext{
$\overline{{ }^{2} \text { DisplaySearch }}$ has been providing reliable information based on manufacturer survey and analyses on the display market and related industries which are widely used in the industry. For India TV market, DisplaySearch provides quarterly updated TV shipment data and analysis of the regional TV market and technology trends.

${ }^{3}$ India's Star Rating registered TVs have accounted for only a few manufacturers and about $20 \%$ of the Indian TV market. While we use the India-specific market data in screen size, market shares of screen technologies, etc., we assume the on-mode power consumption of ENERGY STAR products by screen technology or LCD backlight technology can represent that of the TVs sold in India at that time, as the test methods for both programs are based on IEC 62087.
}

fifth, we estimate the energy-savings potential of such adoption. Finally, we present concluding remarks.

\section{Overview of India TV market}

Total TV shipments for India increased by about $29 \%$ from 2007 to 2011, reaching 15.6 million units, which represent about $6.3 \%$ of global TV shipments in 2011 (DisplaySearch 2009; 2011a; 2012a). Although both global and India TV shipments are expected to decline in the short term until 2013, the shipments are likely to return to growth once the global economy recovers (DisplaySearch 2012b; Morrod 2012). In addition, LCD TVs are expected to overtake CRT TVs in India from 2013 onward. The market share of plasma display panel (PDP) TVs has been less than $1 \%$ of the market, and the shipment is expected to decrease to only 20,000 units (i.e., $0.1 \%$ of the market) in 2014. Fig. 1 shows the estimated India TV shipment and average screen size forecast.

A large-scale global transition from CCFL-LCD TVs to LED-LCD TVs - which are colloquially referred to as "LED TVs" in India-is expected to occur between 2011 and 2015. LED backlights are expected to account for $100 \%$ of the LCD TV market by 2020 (McKinsey and Company 2012). The rapid improvement in LED technologies has driven the adoption of LED backlights for LCD TVs and other applications. In line with the expected increasing demand and rapid technological improvement, costs are expected to fall rapidly as the number of TVs being produced increases. Supply side factors such as relatively high selling prices, better margins, and reduced logistics costs associated with thinner and lighter form factors are also contributing to the global market transition (Park et al. 2011). Although the high selling prices are still a barrier for LCD TVs, including LED-LCD TVs, to penetrate into emerging markets such as India, the penetration rates of LCD TVs in India is expected within the next 3-4 years to be close in percentage terms to that of the global LCD TV market because major manufacturers are planning to provide more affordable LCD TVs in the emerging markets.

\section{Emerging trends - 3D TVs, Smart TVs, and OLED TVs}

We want to discuss these three trends because they all have potential impact on energy consumption of TVs. 


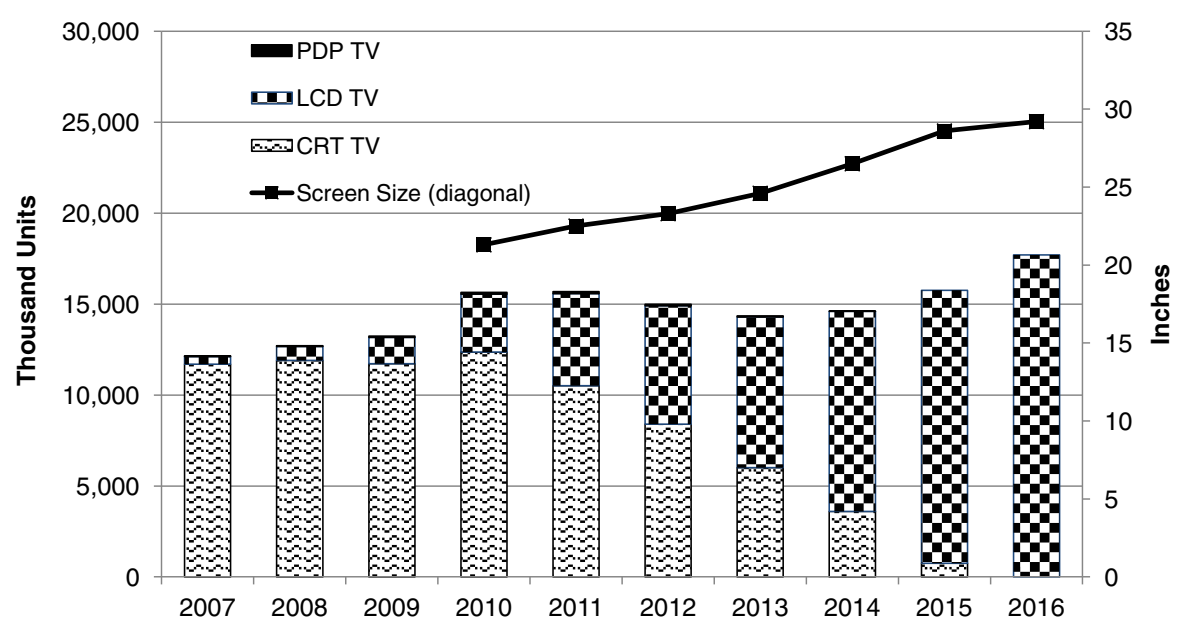

Fig. 1 Actual (2007-2012) forecasted (2013-2016) TV shipments and average screen size in India. Source: DisplaySearch 2009, 2012a. Note: At the time of the study, DisplaySearch was not expecting any more shipments in CRTs and PDPs from 2016 onward, as their market volume is expected to fall below the level that can sustain production
Major manufacturers such as Samsung, LG, Sony, and Panasonic are providing 3D TVs in the Indian market. For example, LG's scope of 3D TV business in the market is getting larger, targeting the equivalent of 184 million USD (Rs. 1,000 crores $=$ Rs. $1,000 \times 10^{7}=$ USD 184 million) from 3D TVs (LG India 2012). The Indian 3D TV market is estimated to account for 4-10\% of the FPD TV market in 2011-2012 and to gradually increase because 3D displays are attractive to game users as well as TV viewers (LG India 2012; Hindu Business Line 2012; SiliconIndia 2011). However, high prices and glasses required to watch $3 \mathrm{D}$ images are still barriers to the uptake of 3D TVs. In addition, growth in the 3D TV market requires available content and internet connectivity improvements.

Current 3D-capable displays in 3D mode require additional image processing and yield a relatively lower brightness level due to additional films or 3D-glasses in comparison to $2 \mathrm{D}$ mode. The overall magnitude of the impact on energy consumption of the shift from 2D to $3 \mathrm{D}$ mode is dependent on manufacturers' strategies to increase brightness and users' subjective tastes, e.g., changes in consumers' viewing time for 3D content. For example, United States Department of Energy (US DOE) conducted their testing in 2010 to determine the effects of 3D content on power consumption for five 3D TVs. The test found that the percent increase in power consumption from 2D to 3D ranged from -21 to $86 \%$ (United States Department of Energy US DOE 2012). Therefore, the impact is difficult to estimate precisely.
Internet-connected TVs, or Smart TVs, ${ }^{4}$ are another recent trend. Smart TVs in India accounted for less than $5 \%$ of the total FPD TV shipments and are expected to be about $50 \%$ of the market by 2017 (Prabhudesai 2012). The growth of the Smart TV market depends on the accompanying applications, user-friendly interface, and a high-performance platform rather than on the screen technology itself. Smart TVs are expected to consume more energy compared to conventional (nonsmart) TVs because of the following factors: advanced signal processing, larger average screen size and increased daily usage, quick start options, and network standby mode (Park et al. 2011, 2013). In particular, although majority of TVs currently consume much less than $1 \mathrm{~W}$ in passive-standby mode, Smart TVs are likely to consume more energy in networked standby mode than conventional TVs. One reason is that such connected TVs can be required to rapidly wake from standby mode. The minimum power requirement for basic network processing for Smart TVs depends on the TV's internal design scheme and specifications, and therefore varies among models from different manufacturers (Park et al. 2011, 2013).

In the global display market, the number of organic light-emitting diode (OLED) displays has been growing

\footnotetext{
"The term "smart TV" would be defined when they include advanced functions (e.g., advanced user interface, intelligent recommendation for users, and platform for user-created functions) in addition to network connectivity (Park et al. 2011).
} 
rapidly in mobile applications. OLED TVs with large screen sizes are expected to begin penetrating into the global TV market through 2013, but only reach sales of 2.7 million units (less than $1 \%$ of the global market) in 2015 (DisplaySearch 2011a). It does not appear that OLEDs will be cost-competitive in the short term against LCD TVs (DisplaySearch 2011a; Park et al. 2011, 2013). For example, starting January 2013, LG began soliciting pre-orders for 55-in. OLED TVs in South Korea. The manufacturer's suggested retail price was 11 million KRW, equivalent to approx. 10,000 USD (Mlot 2013), which is 3-4 times more expensive than the same size LED-LCD TVs sold in the market.

While a comprehensive discussion of consumer behavioral patterns and integrated network features are beyond the scope of this paper which focuses on TV technology and efficiency improvements, the potential increase in TV screen size and corresponding energy consumption increase is included in the analysis. In addition, though we do not focus here specifically on 3D technologies and Smart TVs, all the efficiency improvement options and corresponding cost-effectiveness analysis presented here are also applicable to 3D TVs and Smart TVs. No OLED TV shipment to India is expected to happen until 2016 (DisplaySearch 2012a). This implies that designing market transformation programs to encourage penetration of energy-efficient OLED TVs are still premature. Hence, we have not focused on OLED technology here. As LCD TVs are expected to dominate the Indian TV market from 2013 onward, accounting for about $60 \%$, and expected to reach more than $90 \%$ in 2015, this analysis focuses on LCD TVs.

\section{Efficiency improvement options and related technology trends}

LCD TVs' overall efficiency, if viewed in terms of change in luminance as light travels through the optical processing elements in the display panel, has a significant room for improvement. The final luminance leaving the screen is less than $10 \%$ of the initial luminance available from the backlight source because two crossed polarizers, a color filter, and TFT arrays in the LCD panel collectively absorb or reflect a significant amount of light from the backlight unit (Shieh et al. 2009). The required backlight luminance and the TV energy consumption are thus highly sensitive to the panel transmittance and optical-film efficiency. Therefore, even small efficiency improvements in these components yield large payoffs in terms of required luminance and therefore overall efficiency (Park et al. 2013).

Table 1 summarizes widely accepted LCD TV efficiency improvement options. We here do not provide details of these options and refer readers to Park et al. 2011, 2013 for more detailed information. Although those studies analyzed recently available and dominant technologies in order to identify feasible and costeffective efficiency improvement options, we do not claim that the selected options are the best, the least cost, or the only efficiency improvement options available.

\section{Low-cost LED-LCD TVs trend}

Broadly speaking, TV technology develops in two directions:

- pushing toward adoption of high picture quality and advanced features (e.g., higher resolution, higher frame rate, new backlight system, 3D, and smart features) for early adopters or high-end consumers, and

- toward lower costs for newly developed products for price-sensitive consumers (Semenza 2011).

Developments in both technology directions are not mutually exclusive. Manufacturers plan to implement advanced technology into low-cost models as the technology matures, e.g., entry-level 3D TVs.

In particular, since 2011, major TV manufacturers have been providing new types of LED-LCD TVs at lower prices in the market for the purpose of decreasing the price gap between conventional CRT or CCFL-LCD TVs and LED-LCD TVs. Manufacturers can accomplish this in the following ways. First, decreasing the maximum luminance level and color-reproduction capability reduces material costs as well as power consumption. For example, lower luminance allows manufacturers to use fewer LED lamps as well as low-voltage driven electronic parts in the circuitry (Park et al. 2011). Second, this trend leads to another type of affordable 
Table 1 LCD monitor efficiency improvement options

\begin{tabular}{|c|c|c|c|}
\hline Components & & Improvement Options & Notes \\
\hline \multirow[t]{4}{*}{ Backlight unit } & Backlight source & - CCFL to LED transition & $\begin{array}{l}\text { - Cost increase } \\
\text { - Adopted by manufacturers due to } \\
\text { improved product quality }\left(\mathrm{BAU}^{\mathrm{a}}\right)\end{array}$ \\
\hline & & • High LED efficacy & $\begin{array}{l}\text { - Cost reduction in the longer term (BAU) } \\
\text { - Technical barrier in thermal management } \\
\text { and short-term cost increase from } \\
\text { adoption of much higher efficacy LEDs } \\
\text { than BAU trajectory }\end{array}$ \\
\hline & Optical films & $\begin{array}{l}\text { - Optimized combination of films } \\
\text { - Multi-function film }\end{array}$ & $\begin{array}{l}\text { - Trade-offs in material cost, ease of } \\
\text { manufacture, and efficiency (BAU) }\end{array}$ \\
\hline & & - Reflective polarizer (e.g., DBEF ${ }^{\mathrm{b}}$ ) & - Cost increase, proprietary technology \\
\hline LCD panel & & $\begin{array}{l}\text { - Improvement in panel transmittance by } \\
\text { optimizing pixel design, functional } \\
\text { layers, e.g., polarizer, color filter, and } \\
\text { data line }\end{array}$ & $\begin{array}{l}\text { - Proprietary technology } \\
\text { - R\&D investment required but driven } \\
\text { by potential for total cost reduction. }\end{array}$ \\
\hline \multirow{2}{*}{\multicolumn{2}{|c|}{ Power management }} & - Brightness control by image signals & $\begin{array}{l}\text { - Cost increase } \\
\text { - The effect varies with backlight structure, } \\
\text { input images, and algorithm }\end{array}$ \\
\hline & & $\begin{array}{l}\text { - Brightness control based on ambient } \\
\text { light condition }\end{array}$ & $\begin{array}{l}\text { - Cost increase } \\
\text { - The effect varies with settings and ambient } \\
\text { light condition }\end{array}$ \\
\hline \multirow[t]{2}{*}{ Other } & & - Power supply unit (psu) efficiency & - Trade-off between cost and efficiency \\
\hline & & - Color gamut (by color filter or light source) & - Trade-off with efficiency \\
\hline
\end{tabular}

${ }^{\text {a }}$ Options that are expected to be adopted in a business-as-usual (BAU) case

${ }^{\mathrm{b}}$ Dual brightness enhancement film (DBEF) produced by $3 \mathrm{M}$

Source: Park et al. 2013

LED-direct ${ }^{5}$ backlit LCD TV, often referred to in industry parlance as "low-cost LED-direct backlighting" or "emerging market TVs", which employ about half the LEDs compared to typical LED backlights, and lowercost components, e.g., low-cost diffusion plates in the backlight system (Kim 2012; Semenza 2011). In addition, the maximum luminance of TVs with these backlights is in a range of $300-350 \mathrm{~cd} / \mathrm{m}^{2}$, about $100-150 \mathrm{~cd} /$ $\mathrm{m}^{2}$ lower than the $400-450 \mathrm{~cd} / \mathrm{m}^{2}$ typically found in

\footnotetext{
5 "LED-direct" or "LED full-array" configuration means that the LEDs are uniformly arranged behind the entire LCD panel. Unlike LED-direct models, "LED-edge" or "Edge-lit" configuration means that all of the LEDs are mounted on sides (or edges) of the display.
}

LCD TVs (Kim 2012). However, this type of backlights uses LEDs with wide viewing angles and consequently requires a thicker profile $(25 \sim 40 \mathrm{~mm})$, while conventional LED-edge backlights require less than $10 \mathrm{~mm}$ of thickness. As low-cost LED-direct backlights are intended to replace CCFL backlights and CRT TVs, they are projected to increase the share in the global market up to about $20 \%$ in 2015 (Kim 2012), but the long-term direction of these products is still uncertain because these products require manufacturers to handle another supply chain, due to the thicker profile of TVs, different from other typical LED-LCD TV models.

LCD TVs account for about $43 \%$ of the Indian TV market in 2012, of which LED backlights are $50 \%$, i.e., 
Table 2 Actual (2011-2012) Indian LCD TV market share and forecasted (2013-2015) India LCD TV market share by backlight technology

\begin{tabular}{lllllll}
\hline & & $\begin{array}{l}2011 \\
(\%)\end{array}$ & $\begin{array}{l}2012 \\
(\%)\end{array}$ & $\begin{array}{l}2013 \\
(\%)\end{array}$ & $\begin{array}{l}2014 \\
(\%)\end{array}$ & $\begin{array}{l}2015 \\
(\%)\end{array}$ \\
\hline LCD TVs & 32 & 43 & 58 & 75 & 95 \\
Backlight & CCFL & 25 & 21 & 16 & 10 & 3 \\
& LED & 7 & 22 & 42 & 65 & 92 \\
\hline
\end{tabular}

Source: DisplaySearch 2011a, 2012a; b; c

$22 \%$ of the total Indian TV market (DisplaySearch 2012a). Among the LED-LCD TVs in India, LEDedge, low-cost LED-direct, and high-end LED-direct backlights are estimated to account for 30, 15, and $5 \%$, respectively, in 2012 of the Indian LCD TV market, and the share of low-cost LED-direct backlights is expected to increase as that of CCFL backlights is decreasing (DisplaySearch 2012c; Table 2).

\section{Most efficient commercially available TVs}

The Super-efficient Equipment and Appliance Deployment (SEAD) Global Efficiency Medal competition for FPD TVs ${ }^{6}$ (hereinafter referred as "the SEAD TV Awards") was launched in January 2012 and ran from February to October in the same year. Samsung and LG were recognized as producing the most energyefficient FPD TVs in the world. ${ }^{7}$ The award-winning models are $22-59 \%$ and $32-71 \%$ more efficient than TVs with comparable technology (i.e., LED-LCD TVs) and conventional technology (i.e., CCFL-LCDs), respectively. In fact, the winners in the small- and medium-size categories are affordable entry-level models discussed above (Park 2013).

\footnotetext{
${ }^{6}$ The Super-efficient Equipment and Appliance Deployment (SEAD) Global Efficiency Medal competition for flat-panel display televisions was launched in January 2012. SEAD awarded Samsung and LG for producing the most energy-efficient FPD TVs in the world. More information available at http://www. superefficient.org/

${ }^{7}$ These are most efficient mass market TVs rather than the most efficient TV that is technically feasible. The SEAD TV Awards competition required minimum sales thresholds (Australia 5,000 units; India 5,000 units, North America 50,000 units; the European region 50,000 units across all EU27 and EFTA countries or at least 10,000 units in one country) to ensure that award-winning products have a significant footprint in terms of market share.
}

India was one of the participating governments in the SEAD TV Awards program. The award-winning models for India had not been registered to the Bureau of Energy Efficiency (BEE) Star Rating program. Even though the current 5 Stars level is not stringent, compared to other standards globally, Star-rated TVs comprise only about $20 \%$ of the Indian TV market and a few manufacturers (Park 2013). The on-mode power consumption of the award-winning models is much lower than the (most efficient) 5 Stars specification (see Table 3). These results can inform the revision of Star Rating system in process.

\section{Cost-effectiveness analysis}

TV brands and market prices

While the Indian CRT TV market has been dominated by two India-based (Videocon and Onida) and two Koreabased (Samsung and LG) manufacturers, three Japanese TV manufacturers (Sony, Panasonic and Toshiba) account for about one third of the Indian flat-panel display (FPD) TV market which is rapidly growing (see Fig. 2). In fact, the growing FPD TV market in India is concentrated on fewer key players, compared to the US market. The five "global" manufacturers-Samsung, Sony, LG, Panasonic, and Toshiba - accounted for about $68 \%$ in India and $51 \%$ in North America (DisplaySearch 2011a; 2012a). These major brands distribute similarly designed TVs with similar energy consumption characteristics across many regions.

Although TV manufacturing is highly globalized, market prices of similar TV models produced by one manufacturer vary by region since local market prices are affected by many variables such as import duty, tax, labor, logistics, and brand and reseller margins. Table 4 shows an example of the different market prices of Samsung EH4000 26-in. models which won the smallsize category of the 2012 SEAD Global Efficiency Medals.

Most global TV manufacturers who sell their products in India and the US import LCD panels ${ }^{8}$ from their factories based in their home countries and assemble

\footnotetext{
${ }^{8}$ The term "panel" generally refers to an entire assembly of layers, excluding electronics such as the image circuit and the power supply unit. An FPD "module", also sometimes referred to as "panel", typically refers to a panel with drive circuits.
} 
Table 3 Indian SEAD award-winning models vs. India 5 Stars qualification

\begin{tabular}{|c|c|c|c|c|}
\hline Size category & Model & Brand/ manufacturer & $\begin{array}{l}\text { On-mode power performance }\left[\mathrm{W} / \mathrm{cm}^{2}\right] \\
\text { (on-mode power) }\end{array}$ & $\begin{array}{l}\text { Star rating } 5 \text { Stars } \\
\text { qualification }(\mathrm{W})\end{array}$ \\
\hline Small & UA26EH4000R & Samsung & $0.0134(24.9 \mathrm{~W})$ & 82 \\
\hline Medium & UA40EH5330R & Samsung & $0.0107(47.4 \mathrm{~W})$ & 193 \\
\hline Large & 47LM6700 & LG & $0.0071(43.4 \mathrm{~W})$ & 267 \\
\hline
\end{tabular}

Source: Park 2013

India Star Rating requirements are based on annual energy consumption in kWh per year. Assumptions applied to the above table are as follows: $0.3 \mathrm{~W}$ of standby-mode power; $6 \mathrm{~h}$ of daily usage

those LCD panels with other components in the nearest facilities to the market, e.g., Mexico for the US, and Noida, Pune, or Chennai in India, to produce finished TV sets. Accordingly, it is reasonable to say that the manufacturing costs on LCD panels are nearly same regardless of region. India has imposed an import duty of $10 \%$ on finished TV sets (DisplaySearch 2012d; Ghosh 2009). While the import duty on LCD panels was $10 \%$ and has recently been determined to be zero, the weak rupee to dollar is another factor that influences local pricing (Ghosh 2012a; b). Most TVs imported to the US are produced and assembled in Mexico. The duty for NAFTA ${ }^{9}$ regions is zero on TV sets finished in the region, while the duty on finished LCD TVs imported to the US from other regions, like China, is $5 \%$ (DisplaySearch 2012d).

To estimate markups due to the supply chain for TVs sold in India, it is useful to compare market prices of similar models between two regions. We selected US and India LED-LCD TV models available from 22-24 and 30-34-in. groups of the top five manufacturers (Samsung, Sony, LG, Panasonic, and Toshiba) who accounted for about $68 \%$ of the Indian FPD TV market. The selected product groups are also expected to account for about $75 \%$ of the India TV market by 2015 . In general, TV market price consists of three parts; direct manufacturing costs (e.g., material costs), indirect manufacturing costs (e.g., labor, overhead, freight, etc.), and brand/retailer margins. Direct manufacturing cost is estimated to account for about $70-80 \%$ of the average market price in the US market. Fig. 3 shows a simplified version of the DisplaySearch-modeled cost structure of 22- and 32-in. LED-LCD TVs to be sold in 2013 Q1 in the US market (DisplaySearch 2011b).

\footnotetext{
${ }^{9}$ North American Free Trade Agreement
}

Specification assumptions applied to the DisplaySearch's TV cost model may not be consistent for all brands and all models, but the cost model provides an illustrative guide for determining markups. As discussed earlier, manufacturing costs for LCD panels are nearly the same regardless of region; hence, we assumed TVs with the same brands and specifications in the US and India share the same direct manufacturing cost (i.e., [A] defined in Fig. 3). Table 5 shows an estimated range of markups of 32-in. LED-LCD TVs sold in the US and India.

\section{Cost of conserved electricity}

Cost of conserved electricity (CCE) is a metric used to assess the cost-effectiveness of energy efficiency policies. Estimating CCE for a policy option involves calculating the cost of saving electricity which can then be compared to the cost of providing electricity, to the utility or consumer. ${ }^{10}$ We calculate CCE from two perspectives: First, considering the incremental cost to the manufacturer, which we label $\mathrm{CCE}_{\mathrm{m}}$ and second, the incremental cost to the consumer which includes markups on the incremental manufacturing cost, which we label $\mathrm{CCE}_{\mathrm{p}}$. The former estimate can be used for assessing the cost-effectiveness of upstream incentive programs (e.g., manufacturer incentives), whereas the latter can be used to assess that of downstream incentive (e.g., consumer incentives) or minimum energy performance standards (MEPS) programs (Park et al. 2013).

\footnotetext{
${ }^{10}$ We do not include program administration and implementation costs in this cost-effectiveness analysis, as we are assessing costeffectiveness to the consumer of standards and labeling programs as well as incentive programs.
} 
Fig. 22011 TV shipment distribution in India by brand-CRTs (left) vs. FPDs (right). Source: DisplaySearch 2012a

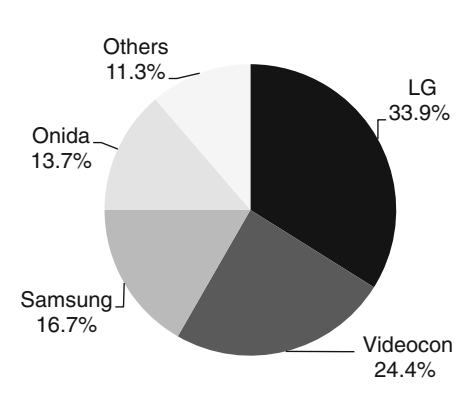

CCE is estimated by dividing the annualized incremental cost (IC) that is required to add the efficiency option by annual energy savings due to the efficiency option. Product categories are defined by screen size and backlight type (e.g., 32-in. LED-LCD TV). The CCE for the $i^{\text {th }}$ product category is calculated using annualized IC for the $i^{\text {th }}$ product category $\left(I C_{i}\right)$ and energy savings for the $i^{\text {th }}$ product category (Energy Savings $s_{i}$ ), as follows:

$$
C C E_{i}=\frac{\text { annualized } I C_{i}}{\text { energysavings }}
$$

where

annualized $I C_{i}=I C_{i}\left[\frac{\text { discount rate }}{1-\left(1+{\text { discount rate })^{- \text {lifetime }_{i}}}\right.}\right]$

$$
\begin{gathered}
\text { Energy Savings }_{i}\left(\frac{\mathrm{kWh}}{\text { year }}\right)=\text { Power reduced }\left(\frac{\text { watts }}{\text { unit }}\right) \times \\
\text { dailyusage }\left(\frac{\text { hours }}{\text { day }}\right) \times \frac{365 \text { days }}{\text { year }} \times \frac{1 \text { kilowatts }}{1000 \text { watts }}
\end{gathered}
$$

where lifetime $_{i}$ is the TVeconomic lifetime, i.e., replacement cycle and discount rate of the end user.

Table 4 Example of market prices of Samsung EH4000 (26 in.)

\begin{tabular}{lll}
\hline Country & Model & Price (USD) \\
\hline Australia & UA26EH4000M & 377 \\
United Kingdom & UE26EH4000W & 317 \\
United States & UN26EH4000F & 260 \\
India & UA26EH4000R & 393 \\
\hline
\end{tabular}

Source: Park 2013

Note: Lowest prices identified from www.getprice.com.au, www. amazon.co.uk, www.amazon.com, compareindia.in.com (as of August 2012)
All TVs in the $i^{\text {th }}$ product category are assumed homogeneous. Thus, total annual energy savings from the $i^{\text {th }}$ product category will be calculated by Energy Savings $_{i}$ times the annual sales of the $i^{\text {th }}$ product category, e.g., annual sales represented by annual shipment of a product category, such as 32-in. LED-LCD TVs.

\section{Energy savings}

Indian Star Rating is a voluntary labeling program. Star rated TVs (blended with flat-panel TVs and CRT TVs) account for about $20 \%$ of the Indian TV market (Park 2013). We estimate energy savings based on the percentage reduction due to efficiency improvements to the baseline LCD TV energy consumption which is based on TVs registered in the US ENERGY STAR database listed on February 2013 (ENERGY STAR 2013). The on-mode power test method ${ }^{11}$ is based on the international standard IEC 62087. ${ }^{12}$ As discussed above, for a given size, display technology, e.g., a 32-in. LED-LCD TV with $1920 \times 1080$ resolution and $60 \mathrm{~Hz}$ frame rate provided by a manufacturer, TVs sold in different regions of the world are similar in terms of the technology and corresponding energy efficiency improvement potential, although there are variations within such a product category. As a result, the information represented by ENERGY STAR registered TVs is applicable to India in terms of illustrating the efficiency improvement potential possible.

\footnotetext{
$\overline{{ }^{11} \text { This analysis }}$ is based on on-mode power data of ENERGY STAR qualified TVs with ABC disabled or without ABC.

${ }^{12}$ We do not use automatic brightness control $(A B C)$ weighted on-mode power values of TVs with ABC enabled, but do on-mode power consumption at 300 lux.
} 


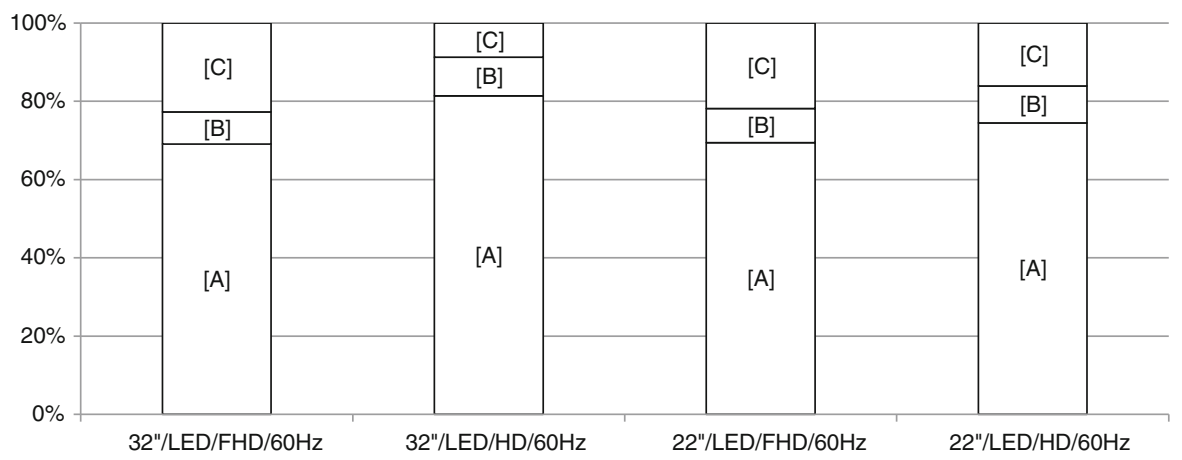

Fig. 3 Cost structure of LED-LCD TVs to be sold in 2013 Q1 in the US. FHD: Full high definition $(1920 \times 1080)$, HD: High definition (1366x768). [A] LCD module + tuner + image processor + audio processor + other mechanical $\&$ electronics + packaging. [B]

\section{Economic lifetime}

The TV replacement cycle on a global scale has decreased from 8.4 to 6.9 years based on the 2011 and 2012 surveys. The average age of the primary TV in households ${ }^{13}$ ranges between 4 and 7 years, with India as the highest at 6.7 years and China-urban the lowest at 3.5 years (DisplaySearch 2012f). In this analysis, the average lifetime of primary TVs in India was assumed to be 7 years. We also perform a sensitivity analysis in the range of 5 to 10 years, to indicate the range encountered in more specific circumstances.

\section{Average usage}

TV usage patterns vary by region, sector of use, consumer lifestyle, and power management scheme applied to the system. Average daily usage of TVs is estimated to range from 3.5 to $6.5 \mathrm{~h}$ (Park et al. 2013). The average on-mode daily usage of TVs in India was assumed to be $6 \mathrm{~h}$ based on the guideline for BEE Star-labeled TVs. We also perform a sensitivity analysis in the range of 4 to $8 \mathrm{~h}$, to indicate the range encountered in more specific circumstances.

\section{Discount rate}

Residential and commercial sectors may use various methods to finance the purchase of appliances. In this

\footnotetext{
${ }^{13}$ The DisplaySearch study includes 14 markets; Brazil, Chinarural, China-urban, France, Germany, India, Indonesia, Italy, Japan, Mexico, Russia, Turkey, UK, US.
}

labor + overhead + profit + warranty + freight + insurance + handling. [C] brand margin + retailor margin Source: Author's calculation based on DisplaySearch 2011b

analysis, we assumed an average discount rate of $15 \%$ for the residential sector based on McNeil et al. 2008 and performed a sensitivity analysis in the range of 5 to $15 \%$ to indicate the range encountered in more specific circumstances. $^{14}$

\section{Estimates of markups}

In this analysis, we used the DisplaySearch TV cost model data (DisplaySearch 2011b) as a baseline for the given set of configurations (i.e., for a 32-in. LED-LCD TV set). We collected Indian retail pricing data online and found that it matches the configuration we derived from the cost model. For this analysis, we assumed a flat $110 \%$ markups based on the results in Table 5.

\section{Residential electricity prices}

Indian electricity tariffs generally use a block structure under which the marginal cost increases with consumption (McNeil et al. 2008). For example, the residential tariffs with $1 \mathrm{~kW}$ capacity and $100 \mathrm{kWh}$ used per month of Andhra Pradesh, Maharashtra, and Karnataka was estimated in 2008 to be in the range of 2.39 to $2.92 \mathrm{Rs}$ per kWh (Abhyankar and Phadke 2012). This analysis is

${ }^{14}$ The $15 \%$ we selected here was based on mid-2000s data. Although the $15 \%$ represents a certain range, $15 \%$ of consumer discount rate is higher than those of other countries. Indian discount rates may eventually decrease as the economy improves. According to Zhuang et al. 2007, there are significant variations in public discount rate policies by countries around the world, with developing countries in general applying higher social discount rates $(8-15 \%)$ than developed countries $(3-7 \%)$. 
Table 5 Estimated Range of Markups of 32-in. LED-LCD TVs

\begin{tabular}{llllll}
\hline Screen size (in.) & $\begin{array}{l}\text { Backlight/ resolution/ } \\
\text { frame rate }\end{array}$ & Country & Market price ${ }^{1}$ (a) (\$) & $\begin{array}{l}\text { Estimated common manufacturing } \\
\operatorname{cost}^{2}(\mathrm{~b})(\$)\end{array}$ & $\frac{(a)-(b)}{(b)} \times 100(\%)$ \\
\hline 32 & LED/FHD/60Hz & US & $349-628$ & 266 & $31-136$ \\
& & India & $554-878$ & 244 & $108-230$ \\
& LED/HD/60Hz & US & $298-535$ & $22-119$ \\
& & India & $506-738$ & $107-202$ & 240 \\
\hline
\end{tabular}

${ }^{1}$ www.amazon.com, compareindia.in.com, www.mysmartprice.com (lowest price among models selected from Samsung, Sony, LG and Panasonic, as of April 2013)

${ }^{2}$ [A] defined in Fig. 4 (DisplaySearch 2011b)

based on the average rate by state based on Indian Power Market 2012.

\section{Product categories analyzed}

Although we assess several efficiency improvement options and analyze their impact on TV electricity consumption, we limit our analysis of cost-effectiveness to those options which are unlikely to be adopted in the absence of policy intervention. For example, as low-cost LED-direct LCD TVs discussed earlier are energy efficient and affordable, the adoption of those products is likely to occur under a business-as-usual (BAU) case. However, even those TVs can be further improved in efficiency with additional options such as advanced optical films or backlight dimming.

To estimate cost-effectiveness, we selected a product group with nominal screen size of 30 34 in. (typical nominal size of 32 in.), representing about $38-40 \%$ of the India LCD TV market, the majority of which are expected to be manufactured without reflective polarizers or backlight dimming in the absence of a policy intervention. These options are currently used primarily for some high-end models with screens larger than 40 in.

Table 6 Share of selected product group in the India LCD TV market

\begin{tabular}{lllll}
\hline Backlight & CCFL & \multicolumn{3}{c}{ LED } \\
\hline Year & 2012 & 2015 & 2012 & 2015 \\
$30 "-34 "$ & $19.4 \%$ & $1.1 \%$ & $19.4 \%$ & $36.7 \%$ \\
\hline
\end{tabular}

Source: DisplaySearch 2012a
The results of our analysis for the selected screen size also hold for other screen size categories since the costs and benefits of adopting the selected efficiency improvement options are generally proportional to screen area, and thus any size variation does not largely affect cost-effectiveness. Although those options can also be applied to CCFL-LCD TVs, we here focus on LED-LCD TVs as the share of CCFL backlights are expected to significantly decrease by 2015 as shown in Table 6.

Three options: reflective polarizers, backlight dimming, and ambient light sensors

As discussed in Park et al. 2011 and 2013, a reflective polarizer improves TV efficiency by 20-30\% regardless of backlight source. Backlight dimming can reduce LCD TV power consumption by $10-60 \%$, depending on input images and dimming methods. ${ }^{15}$ For example, local dimming (or 2D dimming) is possible for earlier discussed low-cost LED-direct backlights, and the efficiency improvement potential is estimated to be up to 50-60\% (Park et al. 2011). Ambient

\footnotetext{
$\overline{15}$ The simplest $\operatorname{dimming}$ option is to dim the whole backlight by a universal amount varying by frame, which is called zerodimensional (0D), complete, or global dimming. This option can be applied to all types of backlights. Backlight auto-brightness control (ABC) can be generally regarded as part of this method. Another option is to dim part of the backlight area depending on input image, which has two variations; (1) one-dimensional (1D), partial, or line dimming, and (2) two-dimensional (2D) or local dimming (Park et al. 2013).
} 
light sensors are commercially available, and their material cost does not vary with screen size or resolution, implying that cost-effectiveness of this option increases with screen size. While backlight dimming in relation to ambient light conditions, i.e., auto-brightness control $(\mathrm{ABC})$, can be generally regarded as part of backlight dimming, more research is needed to estimate the precise effect of these options on household TV energy consumption. As discussed in Park et al. 2013, the material cost of an ambient light sensor was in a range of 0.6 and $\$ 1.0$ per unit as of 2012. The total incremental cost of $\mathrm{ABC}$ for a TV unit with backlight dimming option is estimated to be less than the cost that is required for backlight dimming discussed above.

In this analysis, the product group (i.e., 32-in. LED-LCDs) selected is estimated to have a $\mathrm{CCE}_{\mathrm{m}}$ with a range of $\$ 0.037$ (1.1 Rs) per $\mathrm{kWh}$ and $\$ 0.100$ (5.4 Rs) and a $\mathrm{CCE}_{\mathrm{p}}$ with a range of $\$ 0.079$ (4.3 Rs) per $\mathrm{kWh}$ and $\$ 0.207$ (11.2 Rs) for the year 2015, with assumptions of $15 \%$ discount rate, 7 years economic lifetime, and $6 \mathrm{~h}$ of daily usage (see Table 7). For reflective polarizers and backlight dimming, Figs. 4, 5, and 6 show $\mathrm{CCE}_{\mathrm{m}}$ for LED-LCDs vs. lifetime at various combinations of discount rates and efficiency improvement potential.
Fig. 7 shows the CCEs for the three technical options compared to residential electricity prices of many states in India. The results of our sensitivity analyses indicate that this result would also hold under cases where average residential prices (tariffs) are lower than the marginal residential tariffs (tariff for the last unit consumed which is equivalent to the reduction in consumer bill if one unit of electricity is saved), or vice versa. Thus, TV efficiency can be cost-effectively improved beyond the BAU trajectory using these, or equivalent efficiency improvement options.

\section{Policy insights to accelerate adoption of efficient televisions}

Although we analyzed currently available and dominant technologies in order to identify feasible and cost-effective efficiency improvement options, there is uncertainty regarding precisely which efficiency improvement options will be adopted by manufacturers to meet efficiency requirements. We do not claim that the selected options are the best or only efficiency improvement options available. This analysis does not endorse any specific technology nor advocate prescription of proprietary technology for a standards-setting process or

Table 7 Cost of conserved electricity $(\mathrm{CCE})^{\mathrm{a}}$ for selected options with a 32-in. LED-LCD TV (base year 2015)

\begin{tabular}{|c|c|c|c|c|c|}
\hline Screen size & $\begin{array}{l}\Delta P_{\text {on-mode }}^{\mathrm{b}} \\
\text { per unit }(\mathrm{W})\end{array}$ & $\begin{array}{l}\Delta C_{\mathrm{m}}^{\mathrm{c}} \\
\text { per unit }(\$)\end{array}$ & $\begin{array}{l}\mathrm{CCE}_{\mathrm{m}}{ }^{\mathrm{d}} \\
(\$ / \mathrm{kWh})\end{array}$ & $\begin{array}{l}\Delta C_{\mathrm{p}}^{\mathrm{e}} \\
\text { per unit (\$) }\end{array}$ & $\begin{array}{l}\mathrm{CCE}_{\mathrm{p}}{ }^{\mathrm{f}} \\
(\$ / \mathrm{kWh})\end{array}$ \\
\hline Reflective polarizer & $5.2 \mathrm{~W}$ & 4.3 & 0.091 & 9.0 & 0.191 \\
\hline Backlight dimming & $5.2 \mathrm{~W}$ & 4.7 & 0.100 & 9.8 & 0.207 \\
\hline Ambient light sensor ${ }^{\mathrm{g}}$ & $2.1 \mathrm{~W}$ & 0.7 & 0.037 & 1.5 & 0.079 \\
\hline
\end{tabular}

${ }^{\mathrm{a}}$ Assumptions are discount rate $=15 \%$, economic lifetime $=7$ years, daily usage $=6 \mathrm{~h}$, efficiency improvement $=20 \%$ for reflective polarizer and backlight dimming, $10 \%$ for ambient light sensor

${ }^{\mathrm{b}}$ Average power saving per unit=(average on-mode power of 2015 standard models estimated by authors) - (estimated average on-mode power of 2015 models with selected option)

${ }^{\mathrm{c}}$ Incremental manufacturing $\cos \mathrm{t}=$ (manufacturing cost for 2015 standard models with selected option estimated by authors) - (manufacturing cost for 2015 standard US models predicted by DisplaySearch)

${ }^{\mathrm{d}}$ Cost to the manufacturer of conserved energy which is calculated by Eqs. 1 through 3 at $\mathrm{IC}=\Delta C_{\mathrm{m}}$

${ }^{\mathrm{e}}$ Incremental price $=$ (price for 2015 standard models with selected option estimated by authors) - (average market price for 2015 standard models estimated by authors)

${ }^{\mathrm{f}}$ Cost to the final user of conserved energy which is calculated by Eqs. 1 through 3 at $\mathrm{IC}=\Delta C_{\mathrm{p}}$

${ }^{\mathrm{g}}$ Estimated for TVs with dimming capability 

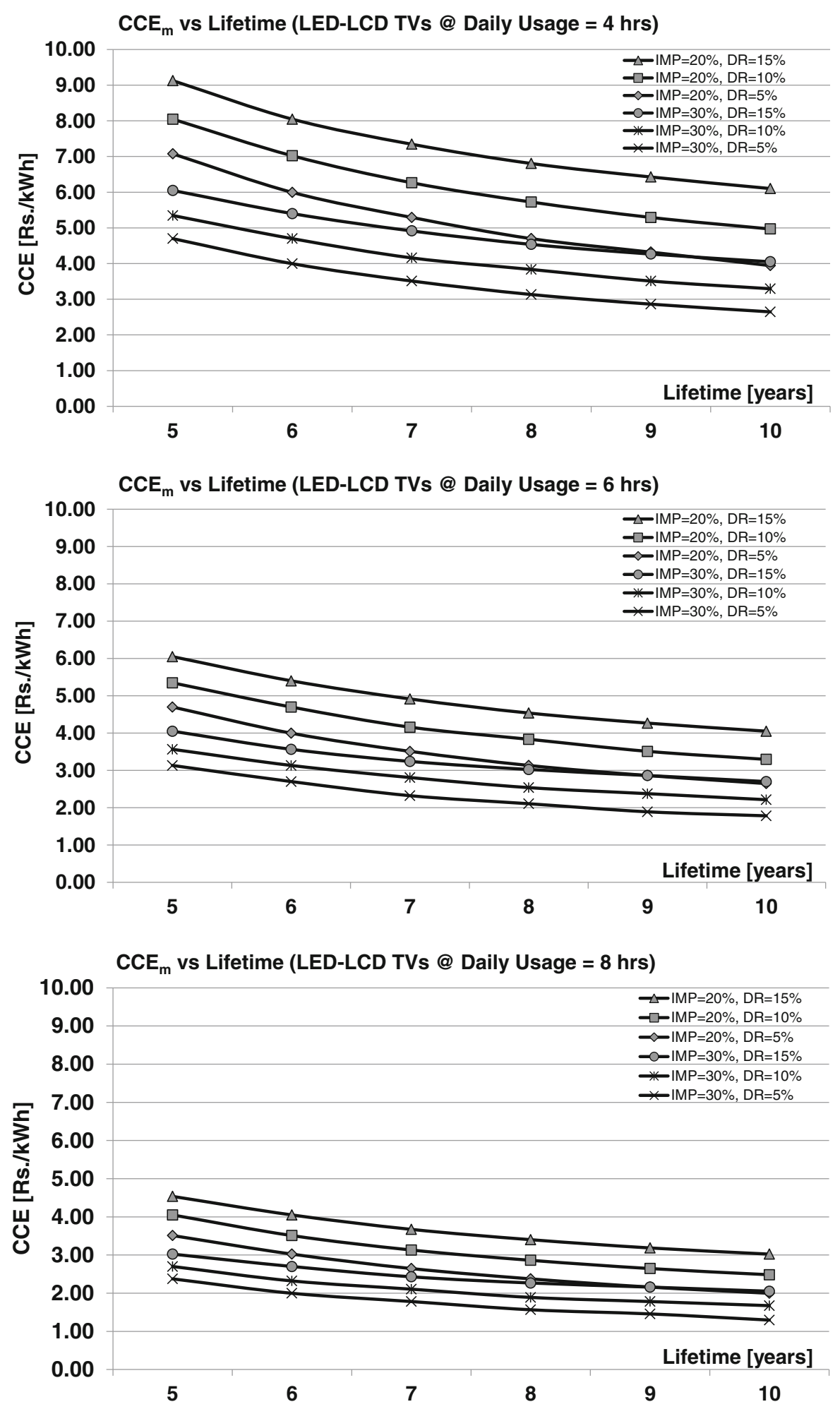

Fig. 4 Sensitivity to lifetime and discount rates of the cost per unit of conserved electricity $\left(\mathrm{CCE}_{\mathrm{m}}\right)$ for reflective polarizers. $1 \mathrm{USD}=54 \mathrm{Rs}$ 

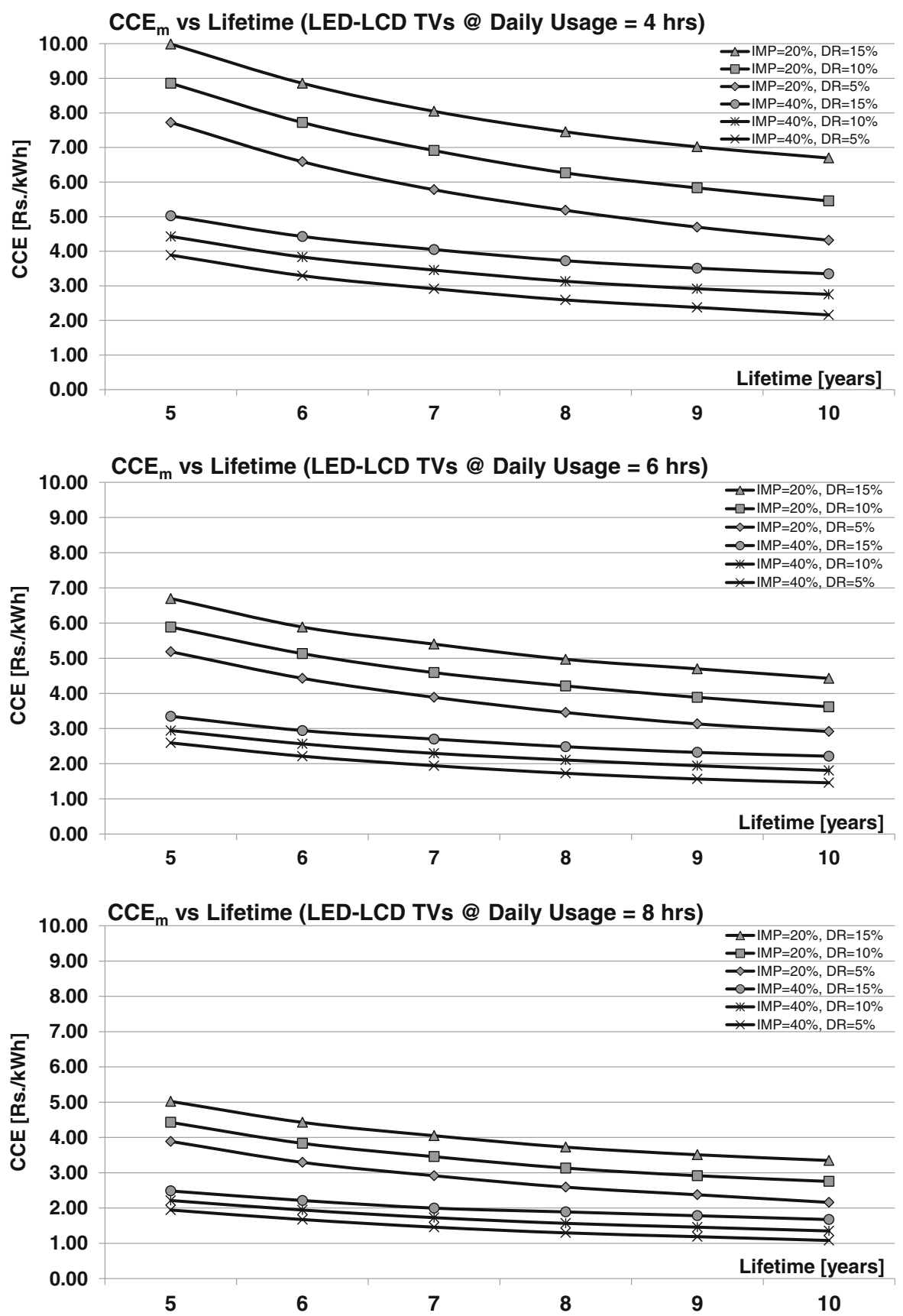

Fig. 5 Sensitivity to lifetime and discount rates of the cost per unit of conserved electricity $\left(\mathrm{CCE}_{\mathrm{m}}\right)$ for backlight dimming. $1 \mathrm{USD}=54 \mathrm{Rs}$

design of incentive programs, but merely discusses certain technologies in order to illustrate the magnitude of cost-effective savings available.
In order to design policies to effectively encourage the efficiency improvement of TVs, it is important to first consider the ongoing market transition, estimate the 

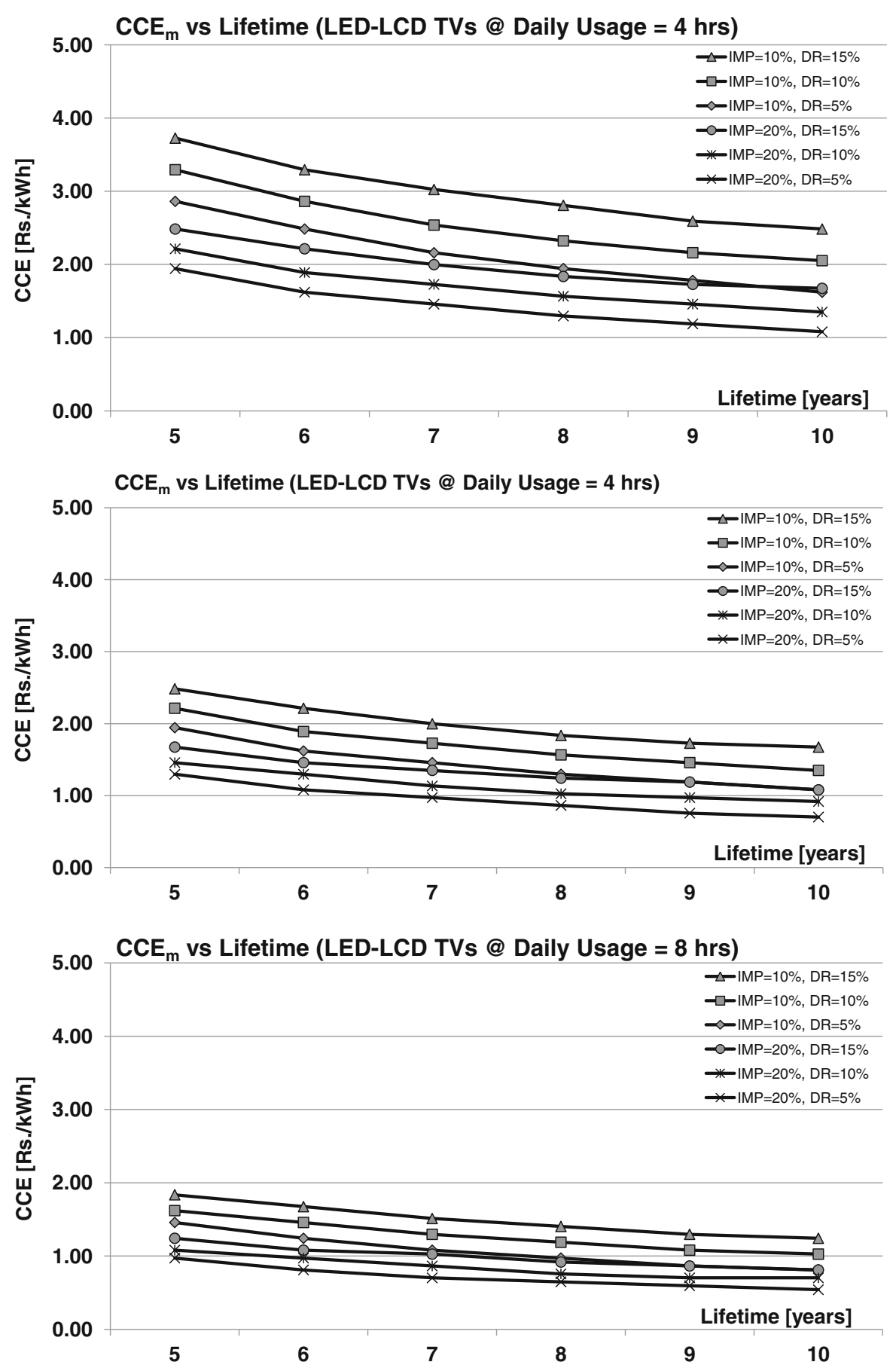

Fig. 6 Sensitivity to lifetime and discount rates of the cost per unit of conserved electricity $\left(\mathrm{CCE}_{\mathrm{m}}\right)$ for ambient light sensor. 1 USD $=54 \mathrm{Rs}$

effect of efficiency improvements that will take place even in the absence of additional policy intervention, and then assess how further efficiency improvements can be facilitated cost-effectively. In addition, efficiency improvements under a BAU scenario, LCD TVs can reduce power consumption using cost-effective options 


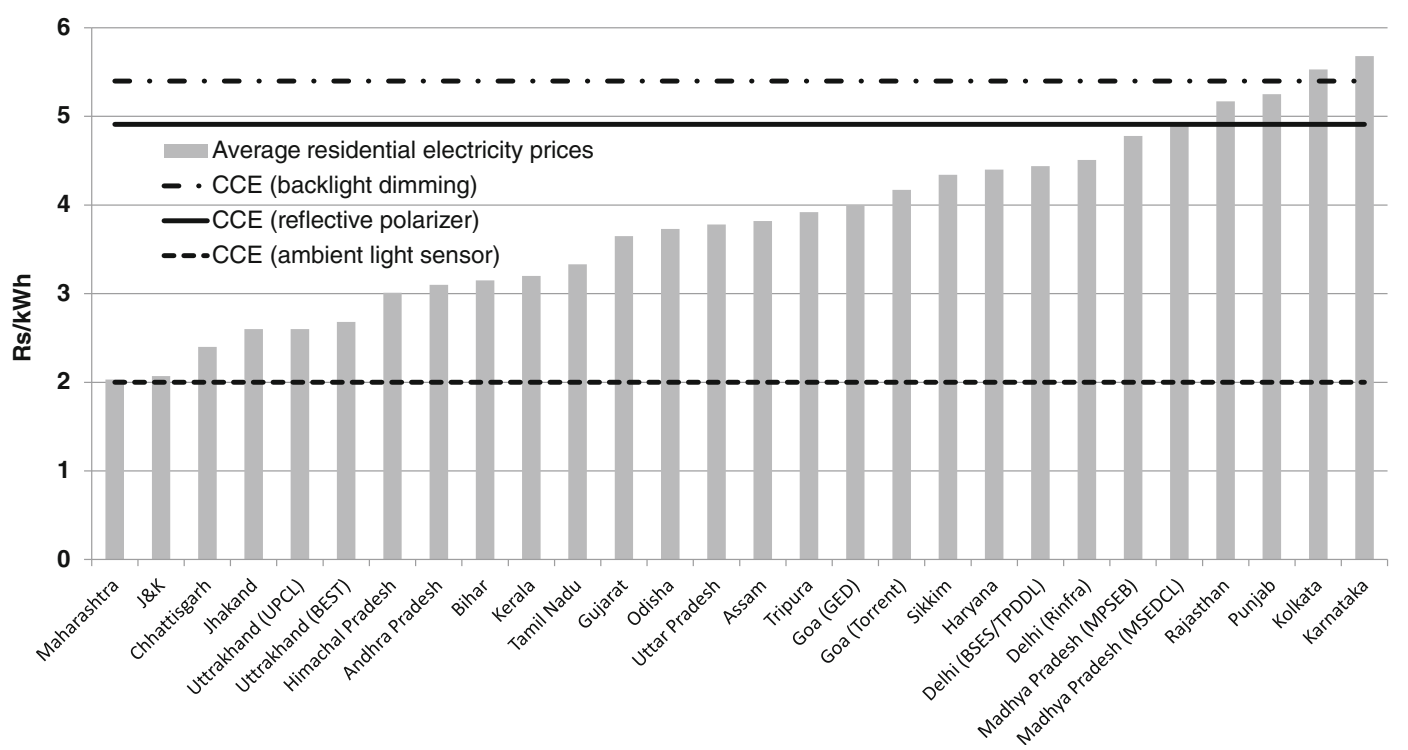

Fig. 7 Average residential electricity prices and cost of conserved electricity (CCE). Source for electricity prices: Indian Power Market 2013. Notes: CCEs with assumptions of assumptions: discount

with $\mathrm{CCE}_{\mathrm{m}}<5.4$ Rs per kWh ( $\left.1 \mathrm{USD}=54 \mathrm{Rs}\right)$, such as reflective polarizers, backlight dimming, and equivalent technology.

Example: Korea's TV energy efficiency standards and labels

South Korea has recently updated its TV standards by reevaluating efficiency. TVs are a product category that was newly included in the Korean Energy Efficiency Label and Standard Program ${ }^{16}$ effective July 2012. However, the share of TVs which qualify grade 1 (most efficient and similar to ENERGY STAR Version 5 specifications) had already reached a market share of $90 \%$ at that time (Korea Energy Management Corporation KEMCO 2012). Korea Energy Management Corporation (KEMCO) had an immediate revision process for the TV efficiency labels and ENERGY FRONTIER ${ }^{17}$

\footnotetext{
$\overline{{ }^{16} \text { The program }}$ has run since 1992 with an aim of energy efficiency improvement in key products including appliances and vehicles that account for majority of energy consumption.

${ }^{17}$ In September 2011, Ministry of Trade, Industry and Energy, which was then the Ministry of Knowledge Economy, and Korea Energy Management Corporation (KEMCO) announced the Energy Frontier program, which sets mid-term energy efficiency goals in key appliances at 30-50\% more efficient than grade 1 (most efficient).
}

rate $=15 \%$, economic lifetime $=7$ years, daily usage $=6$ hours, efficiency improvement $=20 \%$ for reflective polarizer and backlight dimming, $10 \%$ for ambient light sensor

specifications. The Korea TV efficiency label specifications became more stringent by more than $50 \%$ than the previous version in one year (see Table 8).

Potential efficiency levels for Star Rating and potential incentive programs in India

Entry levels (one and/or two stars) of the BEE Star Labeling program setting specifications in 2014-2015 could target an on-mode power consumption level equivalent to ENERGY STAR Version 5 . The majority of LED-LCD TVs available in 2013 are likely to meet the level without $\mathrm{ABC}$ and any further efficiency improvement options (see Fig. 8) and improve efficiency every year even under a BAU case. As LCD TVs are expected to dominate the Indian TV market, amounting to about $95 \%$ of the market by 2015, market transformation programs need to take into account these rapid developments and determine more stringent efficiency targets than are currently in place. Incentive programs setting specifications for 2014-2015 and the higher (i.e., 4 and 5 star) levels of the BEE Star Labeling Program could target an on-mode power consumption level 20-40 \% below ENERGY STAR Version 6 (see Fig. 8). LED-LCD TVs can 
Table 8 Korea regulation on TV efficiency and standards and labels (TVs without network features)

\begin{tabular}{|c|c|c|c|c|}
\hline \multicolumn{2}{|l|}{$R^{\mathrm{a}}$} & \multicolumn{2}{|c|}{$\begin{array}{l}\text { Standby power } \\
\text { (passive-standby mode) }\end{array}$} & \multirow[t]{2}{*}{ Grade } \\
\hline July 1, 2012 & January 1,2013 & July 1, 2012 & January 1, 2013 & \\
\hline $\begin{array}{l}R \leq 91 \& \\
\text { on-mode power } \leq 90 \mathrm{~W}\end{array}$ & $\begin{array}{l}R \leq 35 \\
\text { on-mode power } \leq 25 \mathrm{~W}\end{array}$ & $\leq 1.0 \mathrm{~W}$ & $\leq 0.5 \mathrm{~W}$ & $\begin{array}{l}\text { ENERGY } \\
\text { FRONTIER }^{\mathrm{b}}\end{array}$ \\
\hline$R \leq 130$ & $R \leq 60$ & $\leq 1.0 \mathrm{~W}$ & $\leq 0.5 \mathrm{~W}$ & 1 \\
\hline$R \leq 165$ & $R \leq 75$ & N/A & N/A & 2 \\
\hline $165<\mathrm{R} \leq 205$ & $75 \leq \mathrm{R}<100$ & N/A & N/A & 3 \\
\hline $205<\mathrm{R} \leq 260$ & $100 \leq \mathrm{R}<205$ & $\mathrm{~N} / \mathrm{A}$ & N/A & 4 \\
\hline $260<\mathrm{R} \leq 440$ & $205 \leq \mathrm{R}<440$ & N/A & N/A & 5 \\
\hline
\end{tabular}

${ }^{\mathrm{a}} R=\frac{\text { On Mode Power Consumption }(\mathrm{W})}{\text { Square Root of Screen Area }\left(\sqrt{\mathrm{m}^{2}}\right.}$

${ }^{\mathrm{b}}$ For products with $50 \mathrm{~cm}(\sim 20 \mathrm{in})<$. screen size in diagonal $<180 \mathrm{~cm}(\sim 70$ in. $)$

Source, MKE 2012

achieve this level by adopting cost-effective technologies equivalent in cost and energy savings terms to reflective polarizers and backlight dimming. The efficiency levels achieved by 2012 SEAD TV Award-winning models also support this possibility as shown in Fig. 8.

Based on the above discussion, we show the possibility for new efficiency specifications for TVs in India. Using the current efficiency metric, $P=($ coefficient $\times$ screen area $)+$ constant , the coefficients could be revised. Table 9 shows current and potential new levels, and Fig. 9 shows potential levels, various TV standards, and 2013 ENERGY STAR qualified TVs.

\section{Star (equivalent to the current 5-Star level)}

All TVs, including CRT TVs, currently registered with BEE Star Rating Program qualify for the current 4-Star or 5-Star specifications. As some CRTs meet the current 5-Star level, this level could
Fig. 8 Average on-mode power of $40 \mathrm{in.}$ TVs and various efficiency standards. Note: a (India 5 Stars); b (Korea's Grade 1, July 2012); c (ENERGY STAR Version 5, Sep 2011); d. (ENERGY STAR Version 6, June 2013); e (Korea's Grade 1, July 2013); f (Korea Energy Frontier, July 2013); g (EU EEI A+++)

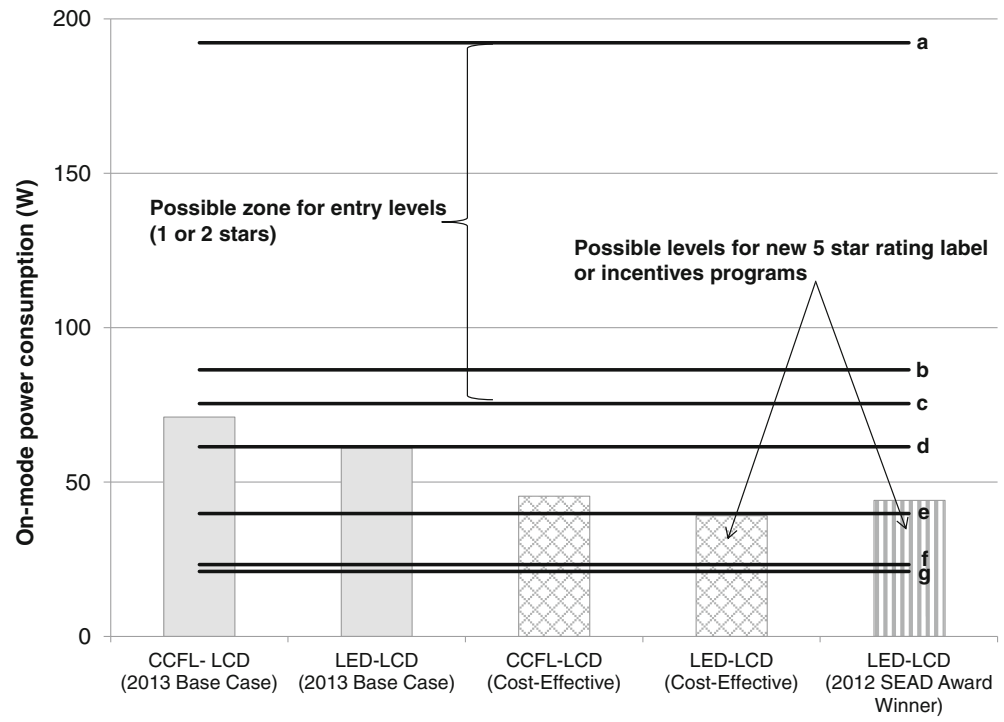


Table 9 Current and potential Star Rating specification equations for TVs

\begin{tabular}{lll}
\hline 2010 to present & $\begin{array}{l}\text { Potential specifications } \\
\text { for 2015 } \\
\text { Max annual power } \\
\text { consumption }(\mathrm{kWh} / \text { year })\end{array}$ & $\begin{array}{l}\text { Rating } \\
\text { consumption }(\mathrm{kWh} / \text { year })\end{array}$ \\
\hline$P=(0.964 \times \mathrm{A})+4.38$ & $P=(0.613 \times \mathrm{A})+4.38$ & 1-Star \\
$P=(0.876 \times \mathrm{A})+4.38$ & $P=(0.307 \times \mathrm{A})+4.38$ & 2-Star \\
$P=(0.788 \times \mathrm{A})+4.38$ & $P=(0.184 \times \mathrm{A})+4.38$ & 3-Star \\
$P=(0.701 \times \mathrm{A})+4.38$ & $P=(0.110 \times \mathrm{A})+4.38$ & 4-Star \\
$P=(0.613 \times \mathrm{A})+4.38$ & $P=(0.066 \times \mathrm{A})+4.38$ & 5-Star \\
\hline
\end{tabular}

$A$ is screen area expressed in square inches

take the place of 1-Star specification in 2015. Additionally, given that only $20 \%$ of TVs on the market have been registered with the Star Rating Program, converting this program from voluntary to mandatory has the potential to also capture additional energy and cost savings for consumers.

\section{Stars ( $50 \%$ more efficient than 1 Star)}

Majority of existing LCD TVs, regardless of backlight technology, are likely to meet potential level equivalent to the potential 2-Star specification. As LCD TVs are expected to account for $95 \%$ by 2015 , the market penetration rate of TVs that meet 2-Star or higher specifications in 2015 is expected to be more than $90 \%$ even without further efficiency improvement in LCD TVs.

\section{Stars ( 70\% more efficient than 1 Star, close to ENERGY STAR Version 6)}

Majority of existing LED-LCD TVs are likely to meet the potential 3-Star specification which is more stringent than ENERGY STAR Version 6 for products less than $40 \mathrm{in}$. Given that TV efficiency is under rapid improvement and the share of LED-LCD TVs is expected to increase, more than $80 \%$ of TVs sold in 2015 are expected to meet the potential 3-Star or higher levels.

\section{Stars ( 80\% more efficient than 1 Star)}

Although only a few models of existing large-size (>50 in.) LED-LCD TVs are currently likely to meet this level, the potential 4-Star specification is achievable by business-as-usual (BAU) improvements (approx. 15-20\% from 2013 to 2015) and/or cost-effective efficiency improvement options (20-40\%) such as advanced optical films and backlight dimming techniques.

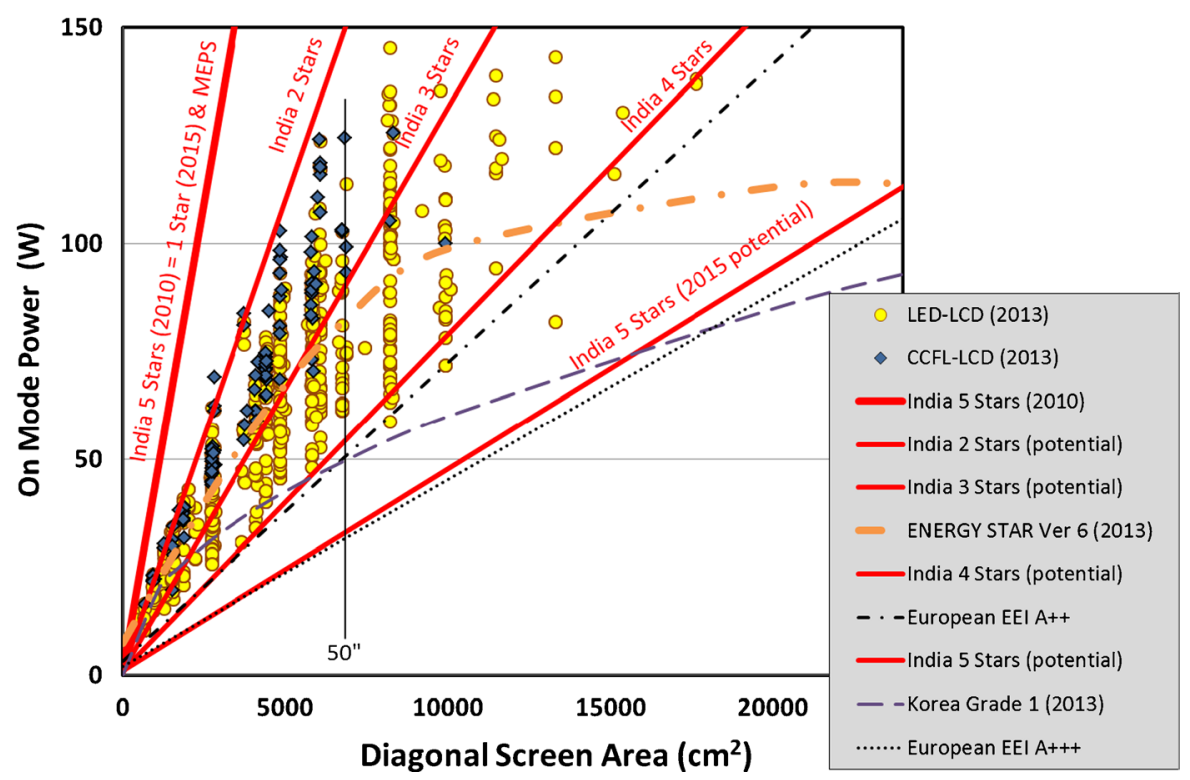

Fig. 9 Potential specifications for India Star Rating vs. ENERGY STAR registered TVs. Note: For TVs with ABC enabled at default home mode, the above data represent on-mode power consump- tion measured at $300 \mathrm{~lx}$. Hence, this data set is comparable with other TV efficiency standards based on IEC 62087 test methods 


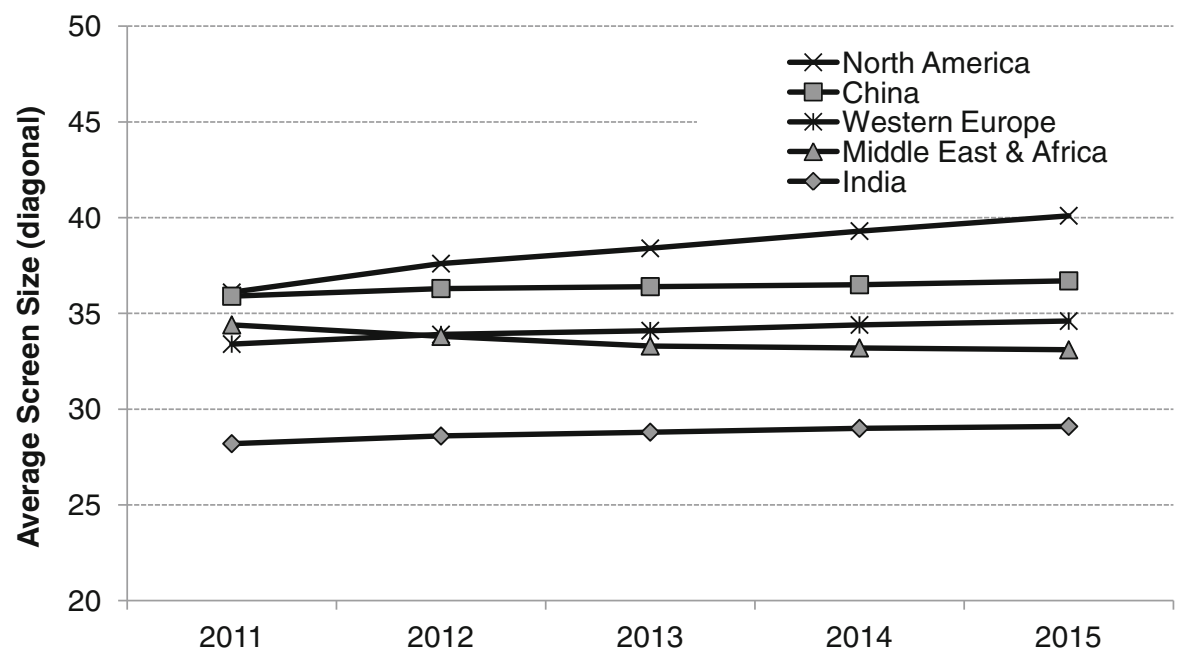

Fig. 10 Actual (2011) and forecasted (2012-2015) average LCD TV screen sizes of various regions. Source: DisplaySearch 2011a, 2012a

5 Stars ( 90\% more efficient than 1 Star, close to EU Energy Efficiency Index (EEI) A+++)

No currently commercially available TVs are estimated to meet this level. This is the level that can be achieved if most efficient models of existing TVs (i.e., TVs barely qualified for 4 Stars) are improved by $40 \%$.

Efficiency metric for maximum power (minimum efficiency) requirement

The efficiency metrics used for India Star Rating, ENERGY STAR (upto and including Version 5), and EU
EEI are generally based on the fact that TV on-mode power consumption correlates with screen area, while additional minimum power consumption is attributable to nondisplay components such as the digital signal processing unit and power supply unit (PSU) (Park et al. 2011). Recent efficiency metric designed for the Korea Energy Efficiency Standards and Labeling Program is based on " $R$ ", defined as on-mode power over square root of screen area, which provides comparatively more stringent specifications for large screens, than for small or medium sizes, compared to conventional linear-scale metrics. For example, Korea's grade 1 specification is more stringent than EU EEI A++ and Australia 10 Stars for products over
Fig. 11 Comparison of TV efficiency standards and labels

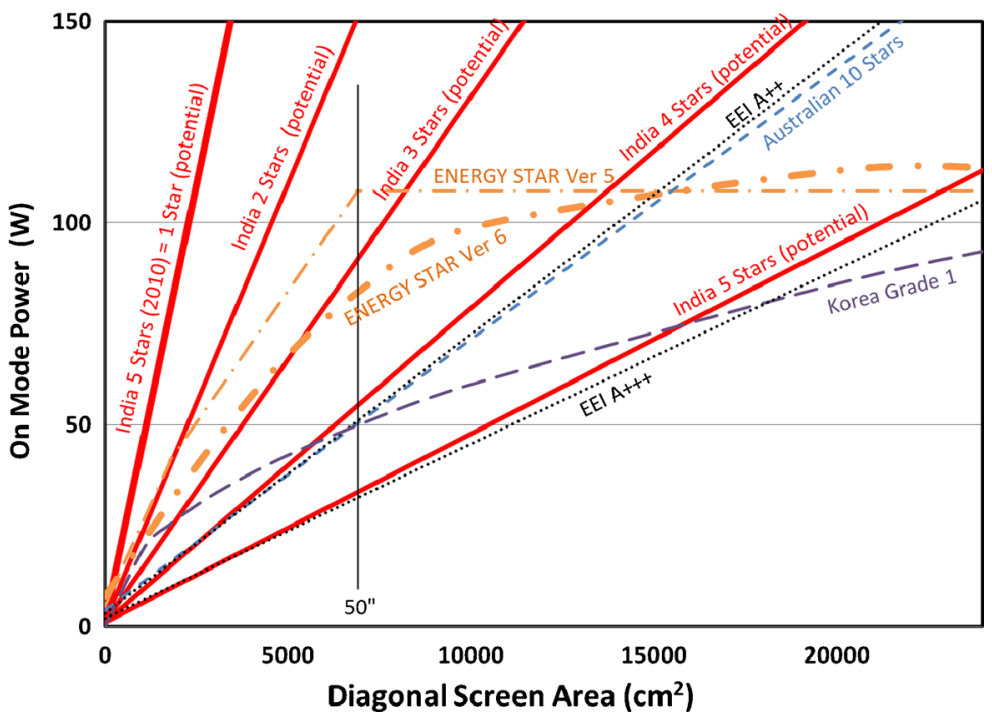


Table 10 Forecast of Indian LCD TV shipments and market share

\begin{tabular}{lllll}
\hline & 2010 & 2013 & 2015 & 2020 \\
\hline Shipments (millions) & 15.6 & 14.4 & 15.8 & $20.8^{\mathrm{a}}$ \\
LCD (CCFL) & $17 \%$ & $16 \%$ & $3 \%$ & $0 \%$ \\
LCD (LED) & $3 \%$ & $42 \%$ & $92 \%$ & $100 \%$ \\
Average screen size (in.) & 28.4 & 28.8 & 29.1 & $29.8^{\mathrm{b}}$ \\
\hline
\end{tabular}

a Authors' estimate based on McKinsey and Company 2011

b Authors' estimate based on the growth rate of average screen size from 2010 to 2015

Source: DisplaySearch 2011a, 2012a, 2012b, 2012c and LBNL's estimates

50 in., but less stringent for those below 50 in. ENERGY STAR has also adopted this type of approach expressed in hyperbolic tangent function (TANH) in Version 6.

The average screen size of TVs sold in India is less than those of other regions (see Fig. 10). TVs with over $50 \mathrm{in}$. are expected to account for less than $1 \%$ of the market in 2015 (DisplaySearch 2012a). Hence, the India TV standards and labels are more critical for small- and medium-size TVs at this stage than large screens. The potential 4-Star and 3-Star specifications outlined here are more stringent than the Korea grade 1 and ENERGY STAR Version 6 for products smaller than 40- and 45in., respectively (Fig. 11).

\section{Estimates of electricity savings potential for efficiency improvement in LCD TVs}

In this section we estimate the energy savings potential of the adoption of efficient technologies discussed above.

Table 11 Estimated average efficiency by technology and scenario

\begin{tabular}{lllll}
\hline & & $\begin{array}{l}2013 \\
\text { average } \\
\text { efficiency }\end{array}$ & $\begin{array}{l}\text { 2015 } \\
\text { average } \\
\text { efficiency }\end{array}$ & $\begin{array}{l}\text { Comparison } \\
\text { with potential } \\
\text { Star ratings }\end{array}$ \\
\hline \multirow{3}{*}{$\begin{array}{llll}\text { Frozen } \\
\text { efficiency }\end{array}$} & CCFL & 0.115 & 0.115 & 2 Stars \\
BAU & LED & 0.095 & 0.095 & 2 Stars \\
& CCFL & 0.115 & 0.098 & 2 Stars \\
Super efficiency & CCFL & 0.115 & 0.063 & 3 Stars \\
& LED & 0.095 & 0.041 & 4 Stars \\
\hline
\end{tabular}

The numbers represented here are based on a 32-in. LCD TVs
Indian TV market data for 2010 to 2016 are available from DisplaySearch. The forecast of TV shipments after 2016 was based on the growth rate of $4 \%$ estimated by McKinsey and Company (2011). We also assume that CRTs, CCFL-LCDs, and PDPs will be phased out of the international market after 2015-2016, in terms of new shipments. Emerging technologies such as OLED TVs were assumed to be included in the LED-LCD category in this analysis as OLED's share in the market is expected to eventually replace LCD's and PDP's. The average screen size of LCD TVs sold in India is expected to be stable from 28 in. in 2010 to 29 in. in 2015 (DisplaySearch 2012a). Hence, in this analysis, the average TV screen size is not assumed to significantly increase by 2020 (Table 10) .

This analysis compares future TV energy consumption for three scenarios: a base case with efficiency improvement expected under a BAU scenario, a superefficiency case, and a frozen efficiency case as follows:

1. Frozen Efficiency - in this case, we assume that there is a large-scale market transition in LCD technology, based on DisplaySearch 2012a, from inefficient (CCFLs) to efficient backlights (LEDs) with no further efficiency improvement within each technology from 2013 onward. In 2015, all existing types of TVs are likely to meet the potential 1-Star (or current 5-Star), 2-Star, and barely 3-Star specifications respectively in this scenario. This case holds the average efficiency of new TVs sold from 2015 to 2020 constant, in order to illustrate by contrast to the BAU scenario, the efficiency improvement that is expected to occur under a the BAU scenario.

2. BAU-The efficiency of CCFL-LCD TVs and LED-LCD TVs is expected to be improved by about 15 and $31 \%$ up to 2015 respectively, compared to 2013 levels (Park et al. 2013). In 2015, the majority of TVs (i.e., LED-LCD TVs) is likely to meet the potential 3-Star specification in this scenario. This case also assumes the average efficiency of new TVs sold from 2015 to 2020 will be improved annually by $5 \%{ }^{18}$

\footnotetext{
18 The efficiency improvement rate after 2015 in TVs is uncertain. However, historically, FPD TV manufacturers have achieved more than $10 \%$ efficiency improvement every year since its introduction.
} 


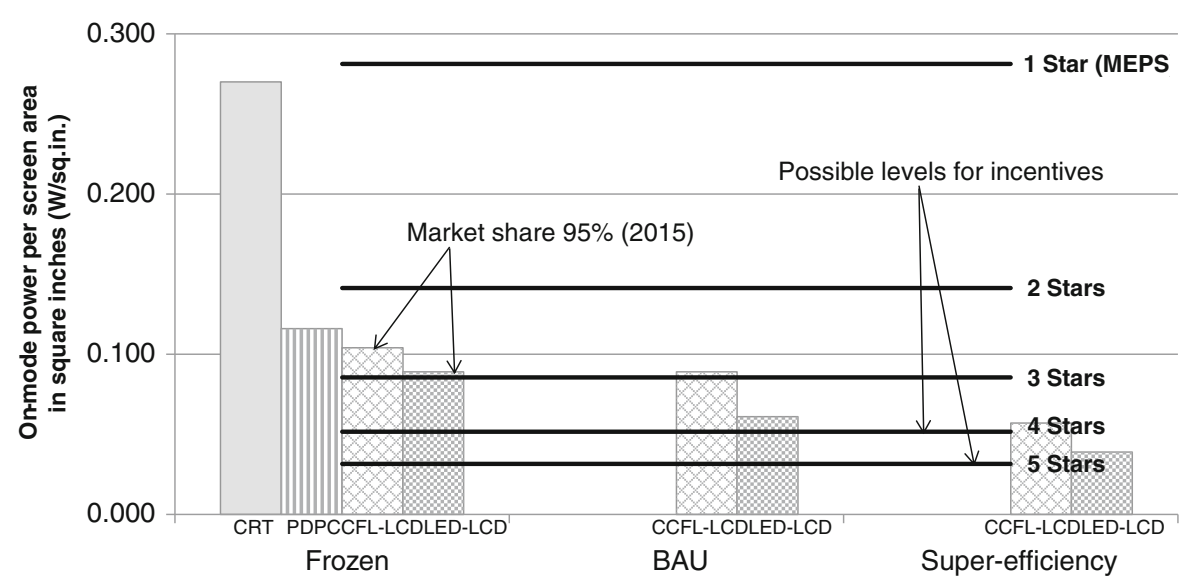

Fig. 12 Average TV efficiency for 2013 vs. potential BEE Star Rating specifications

3. Super Efficiency - this case assumes LCD TVs with efficiency levels equivalent to those achievable by employing additional efficiency improvement options such as advanced optical films and backlight dimming. All LCD TVs employing these options from 2015 are assumed to be about $40 \%$ more efficient than LCD TV models included in the BAU case in the same period. The level that is achievable by LED-LCDs $(0.041 \mathrm{~W} / \mathrm{sq}$.in.) is very close to the potential 5-Star specification, which could be considered as an efficiency level target for incentive programs. In this scenario, we assume that these efficient technologies for LCD TVs can enter the market starting 2015, and in every year, the most efficient designs saturate and reach $100 \%$ of the market. This case also holds the average efficiency of new super-efficient TVs sold from 2015 to 2020 constant.

The above three scenarios are summarized in Table 11 and Fig. 12. The energy savings potential

Table 12 Summary of LCD TV savings potential by scenario

\begin{tabular}{llll}
\hline & $\begin{array}{l}\text { Scenario } \\
\text { compared }\end{array}$ & $\begin{array}{l}\text { Annual } \\
\text { savings } \\
\text { (TWh) } \\
\text { In 2020 }\end{array}$ & $\begin{array}{l}\text { Cumulative } \\
\text { savings } \\
\text { (TWh) }\end{array}$ \\
& & 6.015 through 2020 & 18.2 \\
BAU & Frozen efficiency & 6.0 & 13.4 \\
Super efficiency & BAU & 3.4 & \\
\hline
\end{tabular}

contributed from 2015-2020 TV shipments by each scenario are summarized in Table 12.

\section{Conclusions}

Our analysis finds that a significant decrease in on-mode energy consumption for newly sold TVs in India, as well as other regions, is likely because of the large-scale transition toward LED-LCD TVs and rapid efficiency improvement in display technologies. We also find that TV electricity consumption can be cost-effectively reduced further beyond these improvements. If in every year the efficient designs discussed in this paper reach $100 \%$ of the whole market, the total electricity savings potential would be about 3.4 TWh per year in 2020 and 13.4 TWh from 2015 through 2020 . This savings is achievable by adoption of efficient optical films such as reflective polarizers and backlight dimming techniques, or equivalent technology.

These findings have two implications for energy efficiency market transformation programs in India. First, as a result of the transition and technology improvement, nearly all TVs available in the market are estimated to meet current 4-Star or 5-Star requirements. The Star Rating specifications could be revised and become more stringent. Second, in order to facilitate further improvement in efficiency by the adoption of cost-effective options, market transformation programs need to take into account these rapid developments and determine much more stringent efficiency targets than are currently in 
place. The savings potential estimated in this study may be difficult to capture fully, given the long time it can sometimes take to develop and adopt energy efficiency programs. However, a short-term policy action based on the reliable results presented here can make a difference given that the average economic life time of TVs is about 6-10 years. Furthermore, our results also highlight the open question of the appropriate policy tool to capture these savings fully in a rapidly evolving market. Further research is necessary to address this question fully.

Acknowledgements This work was funded by the Bureau of Oceans and International Environmental and Scientific Affairs, U.S. Department of State, and administered by the U.S. Department of Energy in support of the Super-efficient Equipment and Appliance Deployment (SEAD) Initiative through the U.S. Department of Energy under Contract No. DE-AC02-05CH11231. Any errors or omissions are the authors' own.

Open Access This article is distributed under the terms of the Creative Commons Attribution License which permits any use, distribution, and reproduction in any medium, provided the original author(s) and the source are credited.

\section{References}

Abhyankar, N., \& Phadke, A. (2012). Impact of large-scale energy efficiency programs on utility finances and consumer tariffs in India. Energy Policy, 43(2012), 308-326.

McKinsey and Company (2011). Lighting the way: perspectives on the global lighting market. Edn. 1.

McKinsey and Company (2012). Lighting the way: perspectives on the global lighting market. Edn. 2.

de la Rue du Can et al. (2009). India energy outlook: end use demand in India to 2020. Lawrence Berkeley National Laboratory. LBNL-1751E.

DisplaySearch (2009). India TV market data. Provided by DisplaySearch for the exclusive use only for this study.

DisplaySearch (2010). Quarterly advanced global TV shipment and forecast report. First quarter 2010.

DisplaySearch (2011a). Quarterly advanced global TV shipment and forecast report. Fourth quarter 2011.

DisplaySearch (2011b). Quarterly TV cost \& price forecast model report. Fourth quarter, 2011.

DisplaySearch (2012a). Quarterly India TV shipment and forecast database. Third quarter 2011.

DisplaySearch (2012b). Quarterly global TV shipment and forecast report. Third quarter, 2012.

DisplaySearch (2012c). DisplaySearch's comments on estimated market share of LED backlit LCD TVs in India from 2011 to 2013.

DisplaySearch (2012d). DisplaySearch's comments on import duty for LCD TVs in India.

DisplaySearch (2012e). 2012 TV replacement study for India. Presentation slides. DisplaySearch.
DisplaySearch (2012f). Global TV replacement cycle falls below 7 years, as households continue to replace older CRT TVs and upgrade to larger flat panel sets. http://www.displaysearch. com/pdf/120529_global_tv_replacement_cycle_falls_below_ 7 years as households continue to replace.pdf.

ENERGY STAR (2013). List of ENERGY STAR qualified TVs. Access on Feb 15, 2013.

Ghosh, I. (2009). Indian government reduces import duty on LCD panel. July. http://www.displaysearchblog.com/2009/07/ indian-government-reduces-import-duty-on-lcd-panel/.

Ghosh, I. (2012a). TV brands in India struggle with slow growth and a weak rupee - is direct LED the solution? May. http:// www.displaysearchblog.com/2012/05/tv-brands-in-indiastruggle-with-slow-growth-and-a-weak-rupee-is-direct-ledthe-solution/.

Ghosh, I. (2012b). LCD TV panels to attract zero import duty. March. http://www.displaysearchblog.com/2012/03/lcd-tvpanels-to-attract-zero-import-duty/.

Hindu Business Line (2012). LG bets big on 3D display panels. News article. http://www.thehindubusinessline.com/ industry-and-economy/marketing/lg-bets-big-on-3d-displaypanels/article4064497.ece.

LG India (2012). LG, the leader in Indian TV market plans to occupy $50 \%$ of 3DTV market share. May. http://lgindiablog. $\mathrm{com} / \mathrm{p}=1254$.

India Power Market (2012). Electricity prices in different states of India. September. http://www.indianpowermarket.com/2012/ 09/electricity-prices-in-different-states.html.

International Energy Agency (IEA). (2009). Gadgets and gigawatts - policies for energy efficient electronics. http://www. iea.org/textbase/nppdf/free/2009/gigawatts2009.pdf.

Kim, J. (2012). Lower-cost LED backlights darken CCFL's future. DisplaySearch. May. http://www.electroiq.com/ articles/sst/2012/05/lower-cost-led-backlights-darkenccfl-future.html.

Korea Energy Management Corporation (KEMCO) (2012). KEMCO's comment on market share of Grade 1 qualified TVs. August.

McNeil, M. A., et al. (2008). Potential benefits from improved energy efficiency of key electrical products: the case of India. Energy Policy, 36(2008), 3467-3476.

Ministry of Knowledge Economy (MKE) Korea (2012). Revision of energy efficiency standards and labels.

Mlot, S. (2013). LG shipping \$10,000 55-inch OLED TV next month. PCMAG.COM. News article. http://www.pcmag. com/article2/0,2817,2413745,00.asp.

Morrod, T. (2012). Global television shipments to shrink in 2012 - shipment growth won't return until 2015. October. IHS iSuppli. http://www.isuppli.com/Display-Materials-andSystems/MarketWatch/Pages/Global-Television-Shipmentsto-Shrink-in-2012.aspx.

Park, W.Y. (2013). Assessment of 2012 Global Energy Efficiency medal for televisions. Super-efficient Equipment and Appliance Deployment (SEAD) Initiative. Clean Energy Ministerial. April. http://www.superefficient.org/en/ Activities/ /media/Files/Assessment $\% 20$ of $\% 20$ SEAD $\%$ 20Global\%20Efficiency $\% 20$ Medals $\% 20$ for $\% 20$ TVs FINAL.pdf. 
Park et al. (2011). TV energy consumption trends and energyefficiency improvement options. Lawrence Berkeley National Laboratory. LBNL-5024E. July. http://www. superefficient.org/Activities/Technical\%20Analysis/ SEAD\%20TV\%20Analysis.aspx.

Park, W. Y., et al. (2013). Efficiency improvement opportunities in TVs: Implications for market transformation programs. Energy Policy, 59, 361-372.

Prabhudesai, A. (2012). Indian smart TV market to reach Rs. 54000 Crore by 2017 . October. http://trak.in/tags/business/ 2012/10/23/indian-smart-tv-market-growth/.

Semenza, P. (2011). The TV of the future. Society for Information Display (SID), Information Display, Nov-Dec.
Shieh, H.D., et al. (2009). Eco-display - an LCD TV powered by a battery? National Chiao Tung University, Taiwan. Society for INFORMATION Display (SID).

SiliconIndia (2011). Will 3D TV click in Indian market? April. News article. http://www.siliconindia.com/shownews/Will_ 3D_TV_click_in_Indian_market-nid-81977-cid-2.html.

United States Department of Energy (US DOE) (2012). Television $3 \mathrm{D}$ mode data http://www.regulations.gov/\# !documentDetail;D=EERE-2010-BT-TP-0026-0033.

Zhuang et al. (2007). ERD working paper series no. 94: theory and practice in the choice of social discount rate for cost-benefit analysis: a survey. Asian Development Bank. 